\title{
Low dose triptolide reverses chemoresistance in adult acute lymphoblastic leukemia cells via reactive oxygen species generation and DNA damage response disruption
}

\author{
Haijun Zhao ${ }^{1,5}, *$, Pengcheng Shi, ${ }^{1, *}$, Manman Deng ${ }^{2, *}$, Zhiwu Jiang ${ }^{3}$, Yin Li ${ }^{1}$, Vinodh \\ Kannappan ${ }^{4}$, Weiguang Wang ${ }^{4}$, Peng $\mathrm{Li}^{3}$, Bing $\mathrm{Xu}^{1,2}$ \\ ${ }^{1}$ Department of Hematology, Nanfang Hospital, Southern Medical University, Guangzhou, P. R. China \\ ${ }^{2}$ Department of Hematology, The First Affiliated Hospital of Xiamen University, Xiamen, P. R. China \\ ${ }^{3}$ Guangzhou Institutes of Biomedicine and Health, Chinese Academy of Sciences, Guangzhou, P. R. China \\ ${ }^{4}$ Research Institute in Healthcare Science, Faculty of Science and Engineering, University of Wolverhampton, Wolverhampton, UK \\ ${ }^{5}$ Department of Hematology, Anqing Municipal Hospital of Anhui Medical University, Anqing, P. R. China \\ *These authors have contributed equally to this work \\ Correspondence to: Bing XU, email: xubingzhangjian@126.com \\ Peng Li, email: li_peng@gibh.ac.cn \\ Weiguang Wang, email: w.wang2@wlv.ac.uk
}

Keywords: triptolide, chemotherapy, drug resistance, DNA damage, acute lymphoblastic leukemia

Received: June 30, $2016 \quad$ Accepted: October 19, 2016

Published: November 19, 2016

\section{ABSTRACT}

Chemoresistance represents a major challenge for treatment of acute lymphoblastic leukemia (ALL). Thus, new drugs to overcome chemoresistance in ALL are urgently needed. To this end, we established a cytarabine (araC)-resistant ALL cell line (NALM-6/R), which interestingly displayed cross-resistance towards doxorubicin (ADM). Here we report that low dose of triptolide (TPL), a natural product used for treating inflammatory diseases such as arthritis, could reverse araC and ADM resistance and in NALM-6/R cells as well as primary cells from patients with relapsed or refractory $(R / R) A L L$, reflected by inhibition of cell proliferation and induction of apoptosis in vitro, and repression of tumor growth in vivo in a mouse xenograft model. Mechanistically, these events were associated with impaired mitochondrial membrane potential and increased reactive oxygen species (ROS) production. Co-treatment with TPL and araC or ADM upregulated pro-apoptotic caspase-9 protein, inhibited checkpoint kinase 1 (Chk1) and 2 (Chk2) phosphorylation, and induced fH2A.X (a DNA damage marker). Notably, the combination regimen of TPL and conventional chemotherapeutics also rapidly diminished tumor burden in a patient with $R / R$ ALL. Together, these findings provide preclinical evidence for repurposing use of TPL in combination with chemotherapeutic agents to treat $R / R$ ALL as an alternative salvage regimen.

\section{INTRODUCTION}

Although the remission rate has achieved $>80 \%$ in patients with newly-diagnosed adult acute lymphoblastic leukemia (ALL) with standard induction regimens, a majority of the responding patients eventually become refractory to initial therapy $[1,2] .30-60 \%$ of these patients experience a relapse, despite aggressive chemotherapy regimens for consolidation and maintenance, even after allogeneic stem cell transplantation [3]. The outcome of patients with relapsed or refractory $(\mathrm{R} / \mathrm{R})$ adult ALL remains very poor. Whereas disease-free survival and complete remission of these patients are rare after salvage therapy, most of them die from the original disease [4]. Current chemotherapy for treating ALL involves complex regimens of multiple drugs that are carefully molded in order to eliminate minimal residual disease while spare normal hematopoiesis. However, de novo and acquired multidrug resistance of ALL cells represents the major barrier to the success of chemotherapy. Therefore, 
discovery and development of new drugs to overcome multidrug resistance is urgently needed in treatment of R/R ALL patients.

Natural products, particularly those used for a long time in traditional Chinese medicine, have recently attracted a lot of attention in treatment of cancer, especially in reversing multidrug resistance [6]. Triptolide (TPL) is a diterpenoid epoxide, originally purified from the medicinal plant Tripterygium wilfordii Hook F (commonly known as lei gong teng) whose extracts have been used to treat a variety of diseases such as inflammation and arthritis in traditional Chinese medicine. TPL was structurally characterized in 1972 [5], and has been shown to have anti-inflammatory, immunosuppressive, as well as anticancer activity. Recently, several groups including ours have demonstrated the potential benefit of TPL to overcome chemoresistance in different types of cancer [7-9], such as myeloid leukemia, pancreatic and ovarian cancer. However, the role and underlying mechanism of TPL in reversing chemoresistance in ALL have not been explored yet.

In the present study, we first established an araCresistant ALL cell line (NALM-6/R) by exposure of parental drug-naïve NALM-6 cells to stepwise increasing concentrations of cytarabine (araC), which also displayed cross-resistance towards doxorubicin (ADM). We then found that low dose TPL was able to re-sensitize NALM$6 / \mathrm{R}$ cells to araC as well as doxorubicin(ADM) in vitro and in vivo, in association with production of reactive oxygen species (ROS) and inhibition of checkpoint kinase 1 (Chk1) and 2 (Chk2), resulting in DNA damage, mitochondrial injury, and apoptosis. The regimens combining TPL with araC or ADM were highly active against primary cells obtained from patients with $\mathrm{R} / \mathrm{R}$ ALL. Of note, we also observed that treatment with TPL with conventional chemotherapeutics also rapidly reduced tumor burden in a patient with R/R ALL, without notable toxicity.

\section{RESULTS}

\section{Establishment of a human ALL cell line acquired chemoresistance}

We first established a drug-resistant cell line (designated NALM-6/R) by exposure of the human ALL NALM-6 cells to stepwise increasing concentrations of araC, after which the established NALM-6/R cell line was routinely maintained in the medium containing 5 $\mu \mathrm{M}$ araC. The chemoresistant profile was evaluated by examine cytotoxicity of $\mathrm{araC}$ and other conventional anti-leukemia agents in vitro in parental drug-naïve NALM-6 and -resistant NALM-6/R cells. As shown in Table 1 , the $\mathrm{IC}_{50}$ of araC against NALM-6/R cells $(115.00 \pm 23.12 \mu \mathrm{M})$ was 766 folds higher than that for parental NALM-6 cells $(0.15 \pm 0.07 \mu \mathrm{M} ; p<0.01)$. Interestingly, NALM-6/R cells displayed marked cross-resistance towards $\mathrm{ADM}$, with the $\mathrm{IC}_{50}$ of $\mathrm{ADM}$ in NALM-6/R cells $(4.82 \pm 0.97 \mu \mathrm{M})$ about 43 folds higher than that in parental NALM-6 cells $(0.11 \pm 0.03$ $\mu \mathrm{M} ; p<0.01)$. Of note, there was no cross-resistance to TPL observed in NALM-6/R cells $\left(\mathrm{IC}_{50}=0.032 \pm 0.04\right.$ $\mu \mathrm{M}$ vs. $0.035 \pm 0.03 \mu \mathrm{M}$ for parental NALM- 6 cells; $p>$ $0.05)$. These results demonstrate that NALM-6/R cells, a chemoresistant human ALL cell line established in vitro, are highly tolerated to cytotoxicity of conventional chemotherapeutic agents such as araC and ADM.

\section{Low dose TPL enhances cytotoxicity of araC and ADM in NALM-6/R cells}

The inhibitory effect of TPL, araC and ADM as single agent on growth of NALM-6/R cells was first examined. Neither araC within a concentration range of $0-5 \mu \mathrm{M}$ nor ADM within a concentration range of 0-0.5 $\mu \mathrm{M}$ exhibited significant proliferation inhibition in NALM-6/R cells after $48 \mathrm{~h}$ exposure (Figure 1). However, in the presence of the $\mathrm{IC}_{20}$ concentration (i.e., $10 \mathrm{nM}$ ) of TPL, the $\mathrm{IC}_{50}$ of araC and ADM against NALM-6/R cells were reduced by 20 and 15 times, respectively (Table 2 and Figure 1). These results suggest that low dose TPL might be capable to reverse chemoresistance against araC and ADM in ALL cells.

\section{TPL potentiates araC- or ADM-induced apoptosis in both NALM-6/R cells and primary refractory or relapsed ALL cells}

We then investigated whether the synergistic antitumor effects between triptolide and araC or ADM stem from induction of apoptosis in chemoresistant ALL cells. To this end, NALM-6/R cells were exposed to the highest non-cytotoxic concentrations of $\operatorname{araC}(5 \mu \mathrm{M})$ or $\operatorname{ADM}(0.5 \mu \mathrm{M})$ in the presence or absence of low dose ( $\mathrm{IC}_{20}$ concentration, $10 \mathrm{nM}$ ) TPL for $48 \mathrm{~h}$. Notably, coadministration of low dose TPL significantly increased apoptosis induced by araC or ADM from $10.21 \pm 0.07 \%$ and $5.56 \pm 0.04 \%$ to $52.40 \pm 4.45 \%$ and $24.60 \pm 3.23 \%$ $(P<0.01$ for each case; Figure $2 \mathrm{a}$ and $2 \mathrm{~b})$, respectively. Consistently, combined treatment with $10 \mathrm{nM}$ TPL and sub-toxic concentrations of araC or ADM significantly increased apoptosis in primary cells isolated from $\mathrm{R} / \mathrm{R}$ ALL patients $(\mathrm{n}=12 ; P<0.01$ for each case, compared araC or ADM as single agent; Figure 2c and Table 3). Notably, the regimens combining TPL with araC or ADM were more effective to induce apoptosis in primary $R / R$ B-ALL cells from patients with white blood cell counts $>$ $100 \times 10^{9} / \mathrm{L}$ than those with $<100 \times 10^{9} / \mathrm{L}(P<0.05$; Table $4)$. These findings suggest that TPL might re-sensitize chemoresistant ALL cells to araC or ADM. 
Table 1: Cytotoxicity of TPL, araC ADM against drug-naïve NALM-6 cells and their chemoresistant NALM-6/R counterparts

\begin{tabular}{lcccc}
\hline \multirow{2}{*}{ Agents } & \multicolumn{2}{c}{$\mathbf{I C}_{\mathbf{5 0}}(\boldsymbol{\mu M})$} & $\begin{array}{c}\text { Fold } \\
\text { increase }\end{array}$ & P value \\
\cline { 2 - 3 } & NALM-6 & NALM-6/R & 0.91 & $>0.05$ \\
TPL & $0.035 \pm 0.003$ & $0.032 \pm 0.004$ & 766.67 & $<0.01$ \\
$\operatorname{araC}$ & $0.15 \pm 0.07$ & $115.00 \pm 23.12$ & 43.82 & $<0.01$ \\
$\mathrm{ADM}$ & $0.11 \pm 0.03$ & $4.82 \pm 0.97$ & \\
\hline
\end{tabular}

Note: Cytotoxicity was assessed using the CCK-8 assay.

\section{The combination of araC or ADM with TPL triggers reactive oxygen species (ROS) production and induces mitochondrial injury in ALL cells}

Since mitochondria play a crucial role in regulation of apoptosis, apoptosis is often associated with loss of mitochondrial membrane potential (MMP) [10]. In this context, we then examine the effects of TPL and araC or ADM alone or in combination on MMP. As shown in Figure 3 , whereas exposure to $\operatorname{araC}(5 \mu \mathrm{M})$ or $\mathrm{ADM}(0.5$ $\mu \mathrm{M})$ resulted in a modest decrease in JC-1 aggregates, coadministration of $10 \mathrm{nM}$ TPL with either of these agents sharply reduced JC-1 aggregates (Figure 3a), reflecting loss of MMP (or mitochondrial depolarization), in NALM$6 / \mathrm{R}$ cells (Figure $3 \mathrm{~b}, P<0.001$ compared to each agent alone).

Moreover, considering the important role of ROS in depolarizing mitochondria and inducing apoptosis, we further measured the ROS levels in NALM-6/R cells after exposed to $\operatorname{araC}(5 \mu \mathrm{M})$ or $\mathrm{ADM}(0.5 \mu \mathrm{M}) \pm 10 \mathrm{nM}$ TPL for $12 \mathrm{~h}$. Compared to treatment with each single agent, the combination of TPL with either araC or ADM significantly increased ROS generation by approximately 9 and 5 folds in NALM-6/R cells, respectively. Notably, $2 \mathrm{~h}$ pre-treatment with the ROS scavenger NAC $(30 \mathrm{mM})$ dramatically prevented ROS production induced by TPL plus araC or ADM (Figure 4), resulting in a marked reduction in apoptosis (from $52.40 \pm 4.45 \%$ and $24.60 \pm$ $3.23 \%$ to $24.56 \pm 3.17 \%$ and $14.15 \pm 2.41 \%$, respectively) in NALM-6/R cells (Figure 2b, $P<0.001$ ). These findings indicate that TPL potentiates lethality of araC and ADM in chemoresistant ALL cells likely by inducing ROS generation and mitochondrial injury.

\section{Combined treatment with TPL and araC or ADM disrupts DNA damage checkpoint, resulting in robust DNA damage in NALM-6/R cells}

Both AraC and ADM, known as DNA cross-linking agents, act to induce DNA damage in cancer cells [11, 12], manifested by increased S139 phosphorylation of histone
H2A.X (designated $\gamma \mathrm{H} 2 \mathrm{~A} . \mathrm{X}$ ) at the sites of DNA doublestrand break [13]. As $\gamma \mathrm{H} 2 \mathrm{~A}$.X is commonly used as a marker for DNA damage, we next examined expression of $\gamma \mathrm{H} 2 \mathrm{~A}$.X to monitor the effects of TPL on DNA damage induced by araC or ADM. While TPL did not significantly affected the levels of $\gamma \mathrm{H} 2 \mathrm{~A} . \mathrm{X}$, the combination of TPL with araC or ADM at the indicated doses resulted in a rightward shift of $\gamma \mathrm{H} 2 \mathrm{~A}$.X-FITC fluorescent peak in FACS histograms, indicating increased $\gamma \mathrm{H} 2 \mathrm{~A} . \mathrm{X}$ expression (Figure 5).

Further, Western blot was performed to assess the effects of TPL and araC or ADM alone or in combination on DNA damage checkpoint by monitoring phosphorylation of Chk1 (Ser345) and Chk2 (Thr68), which reflects cytoprotective activation of cell cycle checkpoints in response to DNA damage (e.g., induced by DNA-damaging agents, including araC and ADM) [14]. Notably, co-treatment with TPL markedly diminished phosphorylation of Chk1 and/or Chk2 triggered by araC and ADM, accompanied by a robust increase in $\gamma \mathrm{H} 2 \mathrm{~A} . \mathrm{X}$ expression (Figure 6), consistent with the results of flow cytometric analysis (Figure 5), and cleavage/activation of caspase 9. These findings suggest that disruption of DNA damage checkpoint might also contribute to reversal of chemoresistance by TPL in ALL cells.

\section{The regimen combining TPL and araC is active in vivo in a xenograft mouse model generated from chemoresistant ALL cells}

To validate the anti-leukemia activity of the regimen combining TPL and araC in vivo, we established a xenograft mouse model by intravenous injection with chemoresistant NALM-6/R cells into NSI (NOD-SCIDIL2Rg-/-) mice. Of note, mice treated with TPL plus araC showed a substantial reduction of tumor burden, manifested by a marked decrease inCD45/CD19 doublepositive cells in bone marrow, compared to mice receiving each single agent (Figure 7a). Consistently, histopathology revealed a remarkable reduction of leukemia cell infiltration in bone marrow of mice receiving treatment with TPL plus araC (Figure 7b). Further, average spleen weight of mice treated with TPL plus $\operatorname{araC}(0.17 \pm 0.26 \mathrm{~g})$ 
were significantly lower than those of mice in the control group $(0.31 \pm 0.23 \mathrm{~g})$, as well as each single agent group $(0.28 \pm 0.01 \mathrm{~g}$ for TPL alone and $0.33 \pm 0.56 \mathrm{~g}$ for $\mathrm{araC}$ alone; $P<0.0001$ for each case; Figure 7c). Last, KaplanMeier analysis showed that the combination of TPL with araC significantly prolonged animal survival, compared to TPL or araC alone $(P<0.01$, Figure $7 \mathrm{~d})$.

\section{The combined therapy with TPL and chemotherapeutics rapidly reduces tumor burden in a patient with refractory B-ALL}

Finally, we report the first use of TPL in combination with conventional chemotherapeutic agents to treat one patient with refractory ALL (patient \#2, Table 3), who had no other treatment available when enrolled into this study. This pilot study was conducted with an approval from the Departmental Review Board and the patent's informed consent. Data was collected prospectively. The patient was a 65-year-old female diagnosed with pre B-ALL with complex chromosome abnormalities. Even though two courses of induction chemotherapy including VDCLP and hyper-CVAD/A regimens were administrated, the response assessments unfortunately indicated a minor remission. At enrollment, the patient suffered from severe bone pain and fatigue; the complete blood count (CBC) revealed WBC count of $145 \times 10^{9} / \mathrm{L}$; a high percentage of blasts (60 and
$86 \%$, respectively) were detected on the smears of both peripheral blood (PB) and bone marrow (BM) aspirate; other laboratory tests included a basic metabolic panel, liver and coagulopathy panels, and renal function, which were all unremarkable. Considering the refractory status of the disease together with the results of the clinical tests, TPL in combination with the FA (fludarabine and cytarabine) regimen was then administered as salvage chemotherapy. The dose level of TPL was $100 \mu \mathrm{g} / \mathrm{m}^{2}$ administered in 3 divided doses daily for 7 days, which was routinely used in clinic for treatment of rheumatoid arthritis [15]. TPL-related hematological or extrahematological toxicities, including the most serious side effects of TPL such as renal toxicity, were not observed during the course of treatment. Surprisingly, the patient experienced marked hematological improvement with an $80 \%$ reduction of peripheral blood blasts two weeks after treatment, and complete resolution of bone pain and fatigue. However, the prolonged response to TPLassociated treatment remains to be defined.

\section{DISCUSSION}

Development of salvage regimens for adult patients with ALL has focused on the incorporation of alternative agents with their known roles in this disease. Most of the recently developed regimens involve the use of high-doses

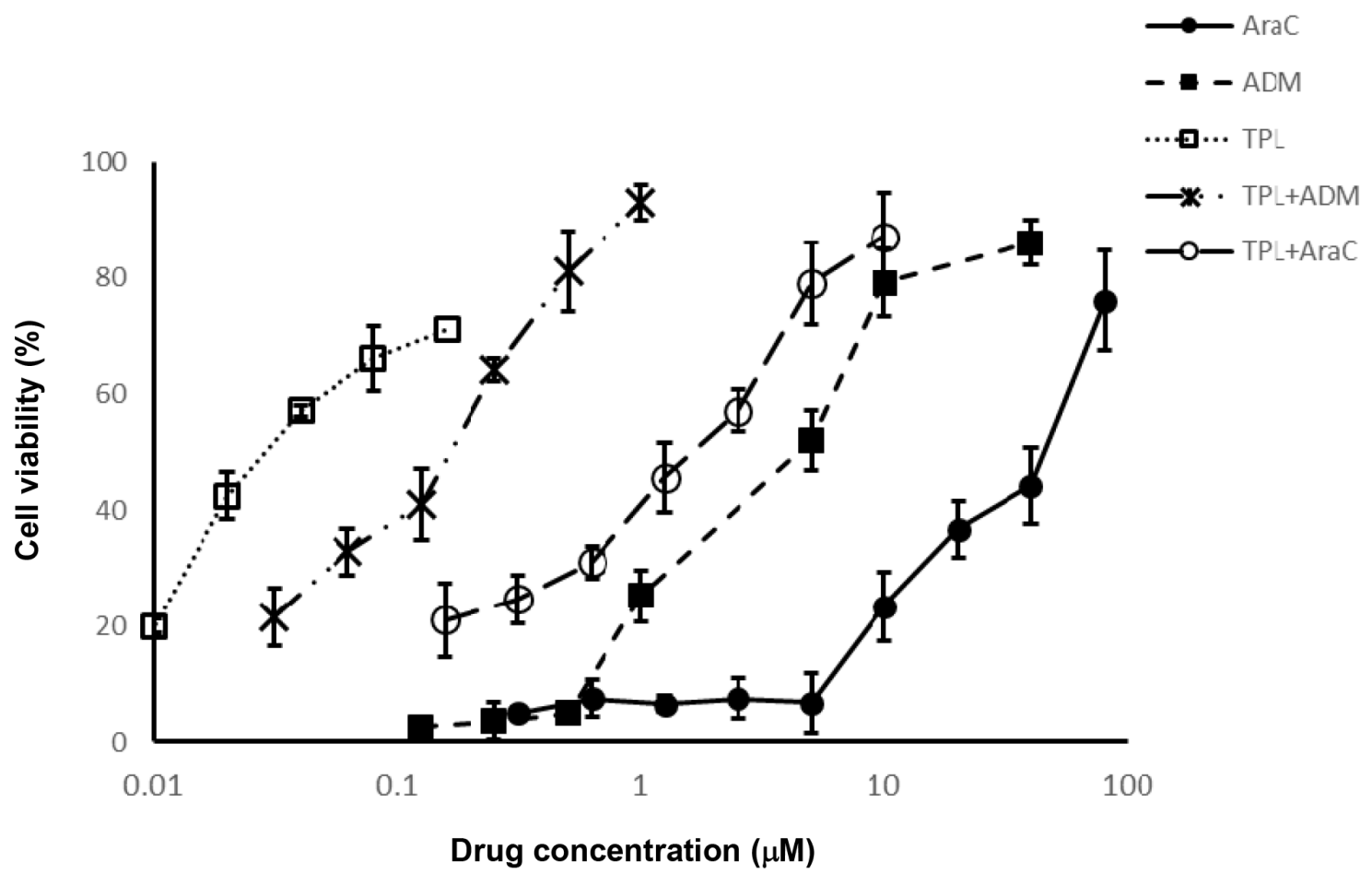

Figure 1: TPL re-sensitizes chemoresistant NALM-6/R cells to araC and ADM. NALM-6/R cells were exposed to the indicated concentrations of $\operatorname{araC}$ or $\mathrm{ADM} \pm \mathrm{TPL}\left(\mathrm{IC}_{20}: 10 \mathrm{nM}\right)$ for $48 \mathrm{~h}$, after which cell viabilities were determined by a CCK-8 assay. Values indicate mean \pm SD for three independent experiments. 
Table 2: TPL-enhanced cytotoxicity of araC or ADM in NALM-6/R cells

\begin{tabular}{lccc}
\hline Agents & IC $_{\mathbf{5 0}}(\boldsymbol{\mu M})$ & Fold decrease & $P$ value \\
\hline AraC & $45 \pm 3.27$ & - & $<0.01$ \\
AraC $\left(+\mathrm{TPL}^{*}\right)$ & $2.25 \pm 0.72$ & 20.00 & $<0.01$ \\
$\mathrm{ADM}$ & $4.85 \pm 0.95$ & - & 15.16 \\
$\mathrm{ADM}\left(+\mathrm{TPL}^{*}\right)$ & $0.32 \pm 0.081$ & & \\
\hline
\end{tabular}

Note: Cytotoxicity was assessed using the CCK-8 assay. * $\mathrm{TPL}=10 \mathrm{nM}\left(\mathrm{IC}_{20}\right.$ concentration $)$.

of araC in combination with various other agents [1619]. However, efficacy of these regimens is significantly hampered by acquired drug-resistance to araC. Therefore, reversal of araC resistance might improve the clinical outcomes of ALL. To this end, we established an araCresistant ALL cell line (NALM-6/R), which unexpectedly was also cross-resistant to ADM. Of note, low dose TPL $(10 \mathrm{nM})$ was able to increase the sensitivity of NALM-6/R cells to araC and ADM by 20 and 15 times, respectively. Further, low dose TPL also significantly increased apoptosis induced by araC and ADM in NALM-6/R cells. We further established a xenograft mouse model using these araC-resistant NALM-6/R cells, in which low dose TPL plus araC was also highly active in vivo, reflected by marked reduction of tumor burden and prolonged animal survival.

Importantly, low dose TPL also dramatically enhanced lethality of araC or ADM in primary leukemia blasts isolated from patients with R/RALL despite the cytogenetic subtypes. It is well established that disease burden at time of relapse is one of the most important prognostic factors of $\mathrm{R} / \mathrm{R}$ ALL [4]. Interestingly, combined treatment with TPL and araC or ADM induced higher percentage of apoptosis in blasts of patients with WBC count $>100 \times 10^{9} / \mathrm{L}$, than those with $<100 \times 10^{9} / \mathrm{L}$, suggesting that this combination regimen might overcome the unfavorable effects of high tumor burden. However, further studies including more cases are needed to confirm this finding. Notably, after received the combination therapy of TPL with conventional chemotherapeutics, a patient with refractory ALL, who had no other treatment available, experienced hematological improvement with $80 \%$ reduction of peripheral blood blasts two weeks later. Taken together, these in vitro and in vivo findings argue strongly that low dose TPL might resensitize chemoresistant ALL cells to conventional chemotherapeutic agents (e.g., araC and $\mathrm{ADM}$ ), and thereby improve the outcome of patients with R/R ALL.

Chemotherapy represents a plethora of challenges to chromosomal DNA. Whereas DNA damage caused by various stimuli has been known to increase ROS levels [20], ROS can in turn induce a wide array of damages to DNA, therefore forming a positive feedback loop. DNA damage-induced ROS is important for determination of cell death versus survival [21]. The ability of cancer cells to distinguish ROS as a pro-survival from a proapoptotic signal is dependent on the amount of ROS. While modest levels of ROS are required for cancer cells to survive, excessive ROS production is lethal to them. It has been reported that drug-resistant cells often have relatively higher basal levels of intrinsic oxidative stress, which might thus lower their threshold to lethal actions of ROS [22]. In the present study, we found that combined treatment with TPL and araC or ADM not only markedly increased ROS production, but also induced robust DNA damage in chemoresistantNALM-6/R cells. Moreover, pre-treatment with the antioxidant NAC attenuated ROS generation triggered by TPL plus araC or ADM, resulting in blockade of apoptosis, suggesting the functional role of elevated ROS levels in reversal of chemoresistance by TPL. Triptolide has previously been demonstrated to induce apoptosis by regulating members of the caspase family, in association with loss of MMP and activation of caspases in cancer cells [23, 24]. Notably, combined treatment with TPL and araC or ADM led to loss of MMP as well as cleavage/activation of caspase-9. Taken together, these findings argue that TPL in combination with araC or ADM triggers ROS production and induces DNA damage, cooperatively leading to activation of the mitochondria-mediated intrinsic apoptosis pathway.

Virtually all DNA-damaging agents currently used in cancer treatment induce apoptosis of cancer cells by inducing substantial DNA damage. It is well established that efficient and continual DNA repair is crucial for normal cells to survive, while it also represents an important mechanism for chemoresistance of tumor cells. Thus, defects or disruption of the DNA damage response (DDR), including DNA damage checkpoint and repair pathways, could sensitize cancer cells to genotoxic agents. For example, the Chk1 inhibitor 7-Hydroxystaurosporine (UCN-01) has been shown to potentiate anti-tumor activity of the DNA-damaging agents such as gemcitabine and cytarabine [25]. DNA cross-linking agents activate checkpoint kinase $1(\mathrm{Chk} 1)$ and 2 (Chk2), which are essential transducer of the DDR [14], which protect cells from lethal effects of genotoxic stress induced by these agents. In the present study, it was found that co-administration of TPL significantly 
$\overline{\mathbf{a}}$
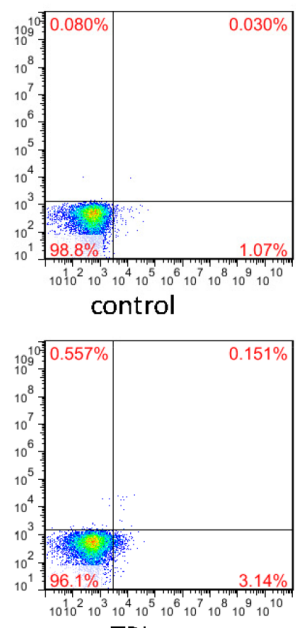

$\mathrm{TPL}_{\mid \mathrm{C} 20}$

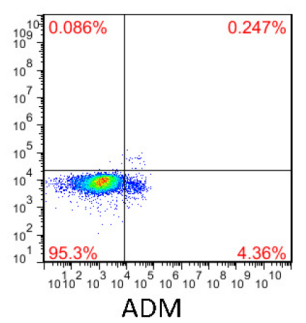

ADM

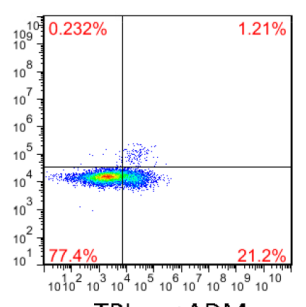

$\mathrm{TPL}_{\mathrm{|C2O}}+\mathrm{ADM}$

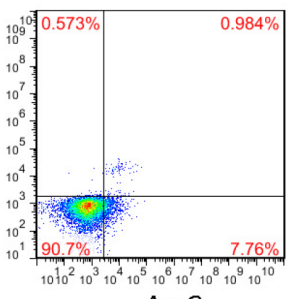

AraC

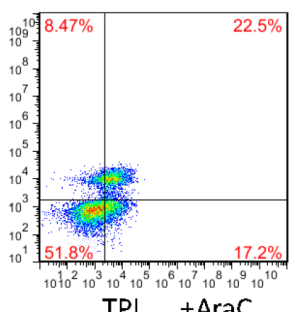

$\mathrm{TPL}_{1 \mathrm{C} 20}+\mathrm{AraC}$

Annexin-V

b

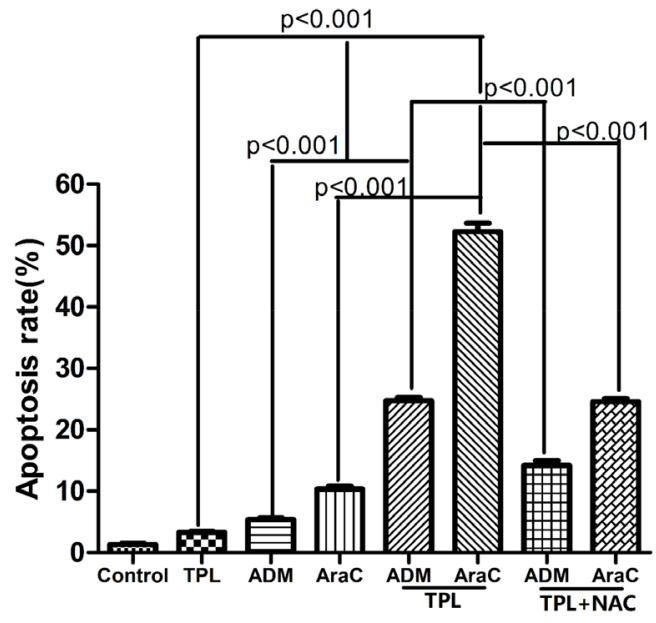

c

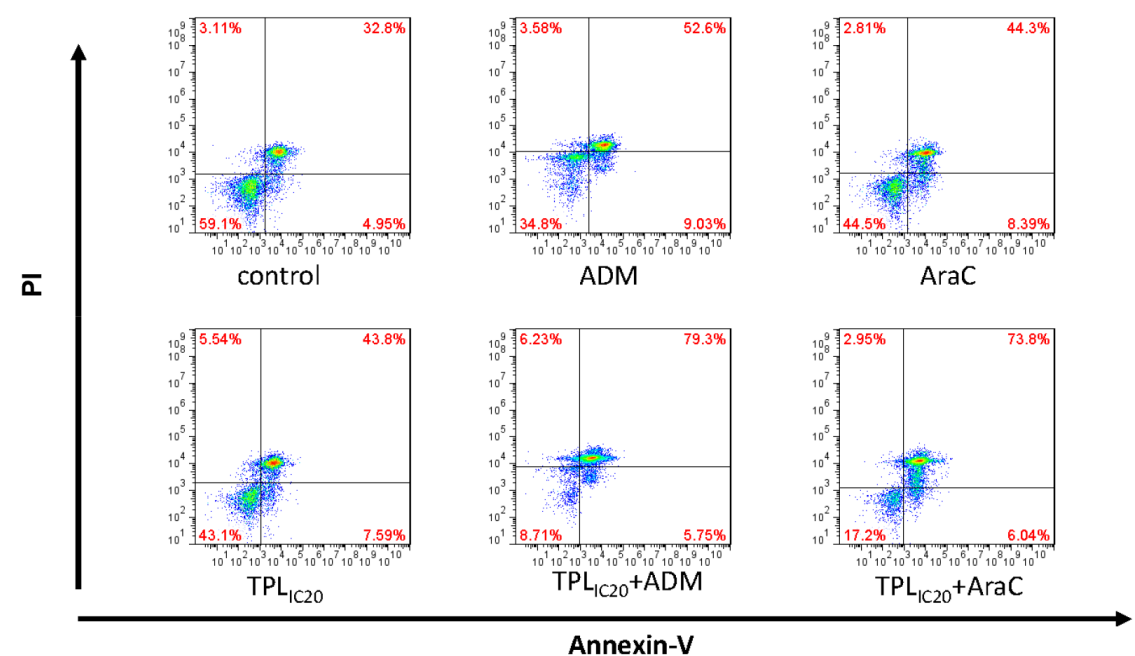

Figure 2: TPL increased apoptosis induced by araC or ADM in NALM-6/R cells, an event blocked by the antioxidant NAC, as well as in primary R/R ALL cells. a. NALM-6/R cells were exposed to araC (5 $\mu \mathrm{M})$ or ADM $(0.5 \mu \mathrm{M}) \pm \mathrm{TPL}\left(\mathrm{IC}_{20}: 10\right.$ $\mathrm{nM}$ ) for $48 \mathrm{~h}$, after which apoptotic ratios were determined by Annexin V/PI staining and flow cytometry. b. A column chart summarizes apoptotic ratios of NAML/R cells after drug treatments as described above for at least three independent experiments (mean $\pm \mathrm{SD}$ ). In addition, $30 \mathrm{mM} \mathrm{NAC}$ was added for $2 \mathrm{~h}$ to block ROS generation prior to combined treatment with TPL plus araC or ADM. c. Primary cells isolated from a patient with R/R ALL (patient \#1 as shown in Table 3 ) were incubated with araC $(5 \mu \mathrm{M})$ or ADM $(0.5 \mu \mathrm{M}) \pm \operatorname{TPL}\left(\mathrm{IC}_{20}: 10\right.$ $\mathrm{nM}$ ) for $48 \mathrm{~h}$, after which apoptosis was analyzed Annexin V/PI staining and flow cytometry. 
Table 3: Effects of the regimens combining TPL with araC or ADM on primary blast cells of refractory or relapsed B-ALL patients $(n=12)$

\begin{tabular}{|c|c|c|c|c|c|c|c|c|c|c|}
\hline \multirow{2}{*}{ No } & \multirow{2}{*}{$\begin{array}{l}\text { Age/ } \\
\text { sex }\end{array}$} & \multirow{2}{*}{$\begin{array}{l}\text { Disease } \\
\text { status }\end{array}$} & \multirow{2}{*}{ Cytogenetic } & \multirow{2}{*}{$\begin{array}{l}\text { Prior } \\
\text { therapy }\end{array}$} & \multicolumn{6}{|c|}{ Apoptotic cells (\%) } \\
\hline & & & & & Con & TPL* & $\operatorname{araC}$ & ADM & $\operatorname{araC}+\mathrm{TPL} *$ & ADM+TPL* \\
\hline 1 & $43 / \mathrm{M}$ & Refractory & $\mathrm{t}(9 ; 22)$ & $\begin{array}{l}\text { TKIs, } \\
\text { VDLP; } \\
\text { Hyper- } \\
\text { CVAD; } \\
\text { Allo-SCT }\end{array}$ & $32.71 \pm 3.13$ & $34.32 \pm 3.65$ & $37.28 \pm 5.70$ & $36.53 \pm 2.65$ & $58.46 \pm 8.78$ & $51.47 \pm 10.16$ \\
\hline 2 & $65 / F$ & Refractory & Complex & $\begin{array}{l}\text { VDCLP; } \\
\text { Hyper- } \\
\text { CVAD }\end{array}$ & $38.70 \pm 4.28$ & $54.84 \pm 3.25$ & $52.76 \pm 4.89$ & $62.31 \pm 5.17$ & $81.76 \pm 3.42$ & $89.27 \pm 4.33$ \\
\hline 3 & $19 / \mathrm{F}$ & Relapse 2 & Complex & $\begin{array}{l}\text { VDLP; } \\
\text { Hyper- } \\
\text { CVAD;FA }\end{array}$ & $34.68 \pm 8.78$ & $38.32 \pm 7.64$ & $43.73 \pm 5.41$ & $56.75 \pm 3.73$ & $59.79 \pm 3.51$ & $67.32 \pm 8.38$ \\
\hline 4 & $35 / \mathrm{M}$ & Refractory & $\mathrm{t}(9 ; 11)$ & $\begin{array}{l}\text { VDCLP; } \\
\text { Hyper- } \\
\text { CVAD;FA }\end{array}$ & $24.71 \pm 6.62$ & $31.32 \pm 6.22$ & $36.28 \pm 4.37$ & $42.62 \pm 8.19$ & $55.26 \pm 7.43$ & $52.15 \pm 8.54$ \\
\hline 5 & $43 / F$ & Refractory & $\mathrm{t}(5 ; 14)$ & $\begin{array}{l}\text { VDCLP; } \\
\text { Hyper- } \\
\text { CVAD }\end{array}$ & $27.52 \pm 7.14$ & $32.25 \pm 2.67$ & $38.78 \pm 3.69$ & $36.62 \pm 10.3$ & $54.52 \pm 4.71$ & $48.25 \pm 3.16$ \\
\hline 6 & $62 / \mathrm{M}$ & Relapse & $\mathrm{t}(9 ; 22)$ & $\begin{array}{l}\text { TKIs, } \\
\text { VDLP }\end{array}$ & $32.56 \pm 5.76$ & $35.24 \pm 3.32$ & $35.35 \pm 5.18$ & $37.22 \pm 4.87$ & $58.29 \pm 4.68$ & $51.61 \pm 5.39$ \\
\hline 7 & $64 / F$ & Relapse 2 & Hypodiploidy & $\begin{array}{l}\text { VDCLP; } \\
\text { CAM; MA; } \\
\text { Hyper- } \\
\text { CVAD }\end{array}$ & $36.28 \pm 6.29$ & $39.11 \pm 2.67$ & $42.68 \pm 3.72$ & $45.51 \pm 5.62$ & $60.37 \pm 4.31$ & $54.49 \pm 7.48$ \\
\hline 8 & $17 / F$ & Refractory & Complex & $\begin{array}{l}\text { VDLP; } \\
\text { Hyper- } \\
\text { CVAD; } \\
\text { VDCLP }\end{array}$ & $27.40 \pm 8.13$ & $31.28 \pm 3.42$ & $34.63 \pm 5.75$ & $32.48 \pm 4.22$ & $44.32 \pm 8.78$ & $36.71 \pm 4.95$ \\
\hline 9 & $37 / \mathrm{M}$ & Relapse & $\mathrm{t}(4 ; 11)$ & $\begin{array}{l}\text { VDCLP; } \\
\text { CAM }\end{array}$ & $26.52 \pm 3.68$ & $32.61 \pm 7.73$ & $37.31 \pm 6.15$ & $30.22 \pm 5.34$ & $42.86 \pm 6.38$ & $34.47 \pm 9.59$ \\
\hline 10 & $26 / F$ & Refractory & $\mathrm{t}(9 ; 22)$ & $\begin{array}{l}\text { TKIs, } \\
\text { VDLP; } \\
\text { Hyper- } \\
\text { CVAD }\end{array}$ & $31.74 \pm 4.23$ & $36.56 \pm 3.46$ & $38.51 \pm 5.76$ & $38.25 \pm 6.48$ & $48.42 \pm 6.73$ & $41.67 \pm 5.98$ \\
\hline 11 & $59 / \mathrm{M}$ & Refractory & Complex & $\begin{array}{l}\text { VDCLP; } \\
\text { CAM;MA }\end{array}$ & $36.86 \pm 4.37$ & $36.17 \pm 2.36$ & $41.51 \pm 3.45$ & $40.69 \pm 5.78$ & $46.87 \pm 6.22$ & $44.54 \pm 5.34$ \\
\hline 12 & $28 / \mathrm{F}$ & Relapse 2 & Complex & $\begin{array}{l}\text { VDCLP; } \\
\text { CAM;MA; } \\
\text { Hyper- } \\
\text { CVAD }\end{array}$ & $24.73 \pm 3.74$ & $31.28 \pm 4.38$ & $34.21 \pm 3.67$ & $37.27 \pm 5.38$ & $39.18 \pm 6.23$ & $44.02 \pm 7.43$ \\
\hline
\end{tabular}

Note: Percentage of apoptotic cells was determined by Annexin V/PI staining and flow cytometry. Values indicate mean \pm SD for at least triplicate experiments. $* \mathrm{TPL}=10 \mathrm{nM}\left(\mathrm{IC}_{20}\right.$ concentration).

Relapse 2, patients with second relapse; Allo-SCT, allogeneic stem cell transplant; TKIs, tyrosine kinase inhibitors (imatinib or dasatinib; $\mathrm{VD}(\mathrm{C}) \mathrm{LP}$ : vincristine, daunorubicin, (cyclophosphamide), L-Asparaginase and prednisone; Hyper-CVAD: hyper-fractionated cyclophosphamide, vincristine, doxorubicin, and dexamethasone, alternating with high-dose methotrexate and cytarabine; FA: fludarabine and cytarabine; MA: mitoxantrone and cytarabine; CAM: cyclophosphamide, cytarabine, and 6-mercaptopurine. 
Table 4: The relationship between WBC count and cytotoxicity of the regimens combining TPL with araC or ADM in primary refractory or relapsed B-ALL cells

\begin{tabular}{|c|c|c|c|c|c|c|c|c|}
\hline \multicolumn{2}{|c|}{$\begin{array}{l}\text { WBC at biopsy } \\
\left(\times 10^{9} / \mathbf{L}\right)\end{array}$} & \multirow[t]{2}{*}{ Con } & \multirow[t]{2}{*}{ TPL* } & \multirow[t]{2}{*}{$\operatorname{araC}$} & \multirow[t]{2}{*}{ ADM } & \multirow[t]{2}{*}{$\operatorname{araC}+\mathrm{TPL} *$} & \multirow[t]{2}{*}{ ADM+TPL* } & \multirow[t]{2}{*}{$P$ value } \\
\hline Median & 114 & & & & & & & \\
\hline Range & $23-146$ & & & & & & & \\
\hline$>100$ & $\mathrm{n}=7$ & $33.74 \pm 4.83$ & $39.37 \pm 8.25$ & $42.87 \pm 6.46$ & $45.85 \pm 11.52$ & $61.36 \pm 10.12$ & $59.67 \pm 15.12$ & $<.05$ \\
\hline$<100$ & $\mathrm{n}=5$ & $30.93 \pm 4.23$ & $35.01 \pm 4.23$ & $38.07 \pm 3.27$ & $37.15 \pm 4.04$ & $42.52 \pm 3.61$ & $40.08 \pm 5.72$ & \\
\hline Total & $\mathrm{n}=12$ & $32.57 \pm 4.62$ & $37.56 \pm 6.98$ & $40.87 \pm 5.73$ & $42.23 \pm 9.92$ & $53.51 \pm 12.44$ & $51.50 \pm 15.44$ & $<.01$ \\
\hline
\end{tabular}

Note: Percentage of apoptotic cells was determined by Annexin V/PI staining and flow cytometry. Values indicate mean \pm $\mathrm{SD}$ for the indicated number of patients. ${ }^{*} \mathrm{TPL}=10 \mathrm{nM}\left(\mathrm{IC}_{20}\right.$ concentration $)$.

a

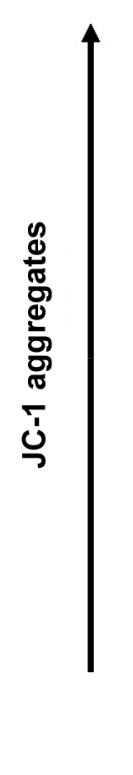

$\mathrm{b}$
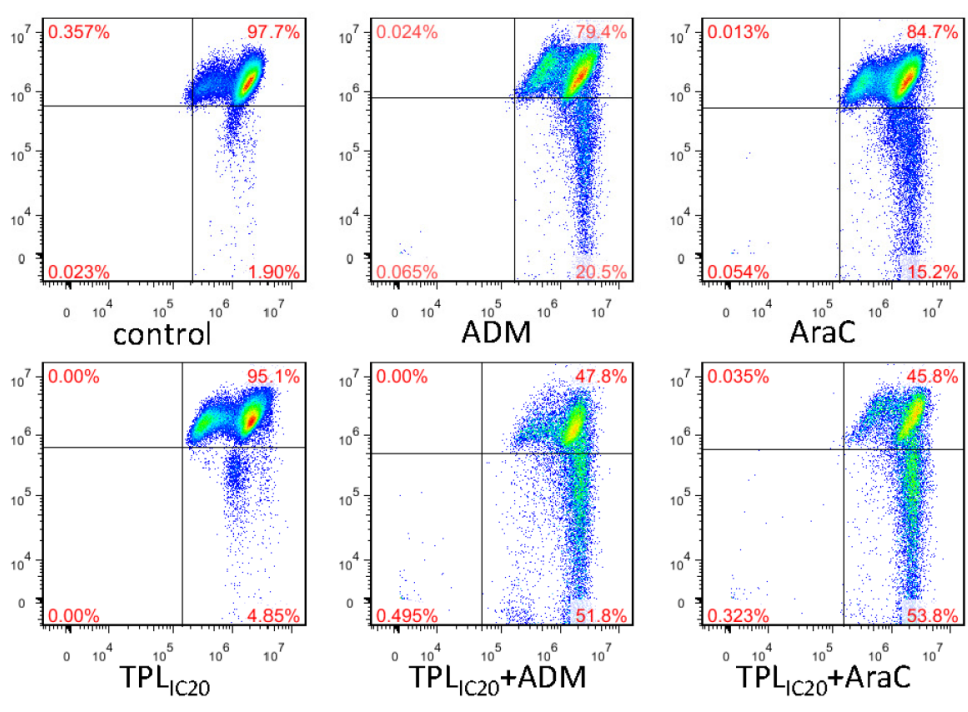

JC-1 Monomers

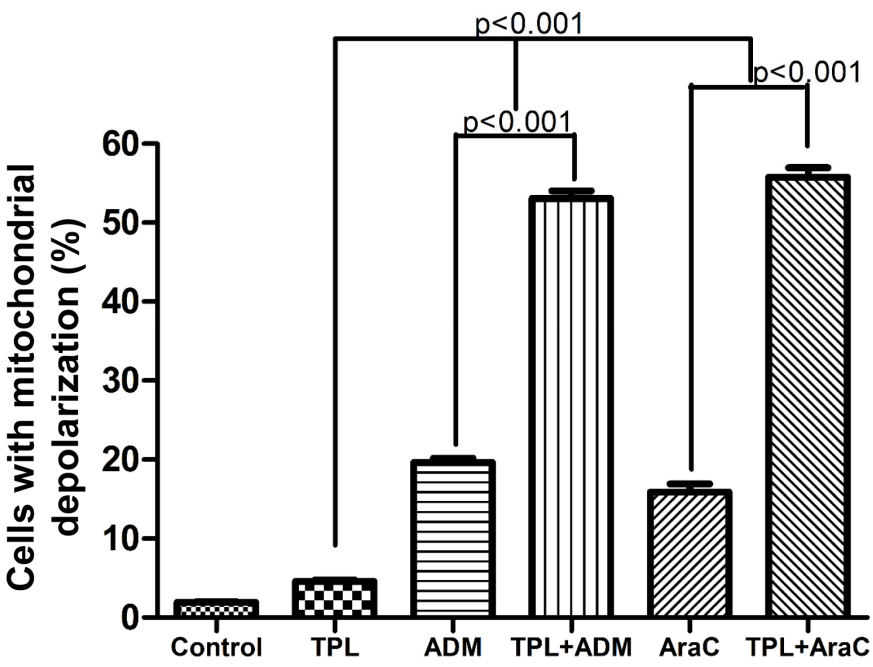

Figure 3: Combined treatment with TPL and araC or ADM results in mitochondrial injury in NALM-6/R cells. a. NALM-6/R cells were exposed to $\operatorname{araC}(5 \mu \mathrm{M})$ or ADM $(0.5 \mu \mathrm{M}) \pm \mathrm{TPL}\left(\mathrm{IC}_{20}: 10 \mathrm{nM}\right)$ for $48 \mathrm{~h}$, after which mitochondrial membrane potential $(\Psi \Delta \mathrm{m})$ was determined by monitoring JC-1 aggregates using flow cytometry. b. A column chart summarizes percentages of NAML/R cells with loss of $\Psi \Delta \mathrm{m}$ (or mitochondrial membrane depolarization) after drug treatments as described above for at least three separate assays (mean $\pm \mathrm{SD}$ ). 


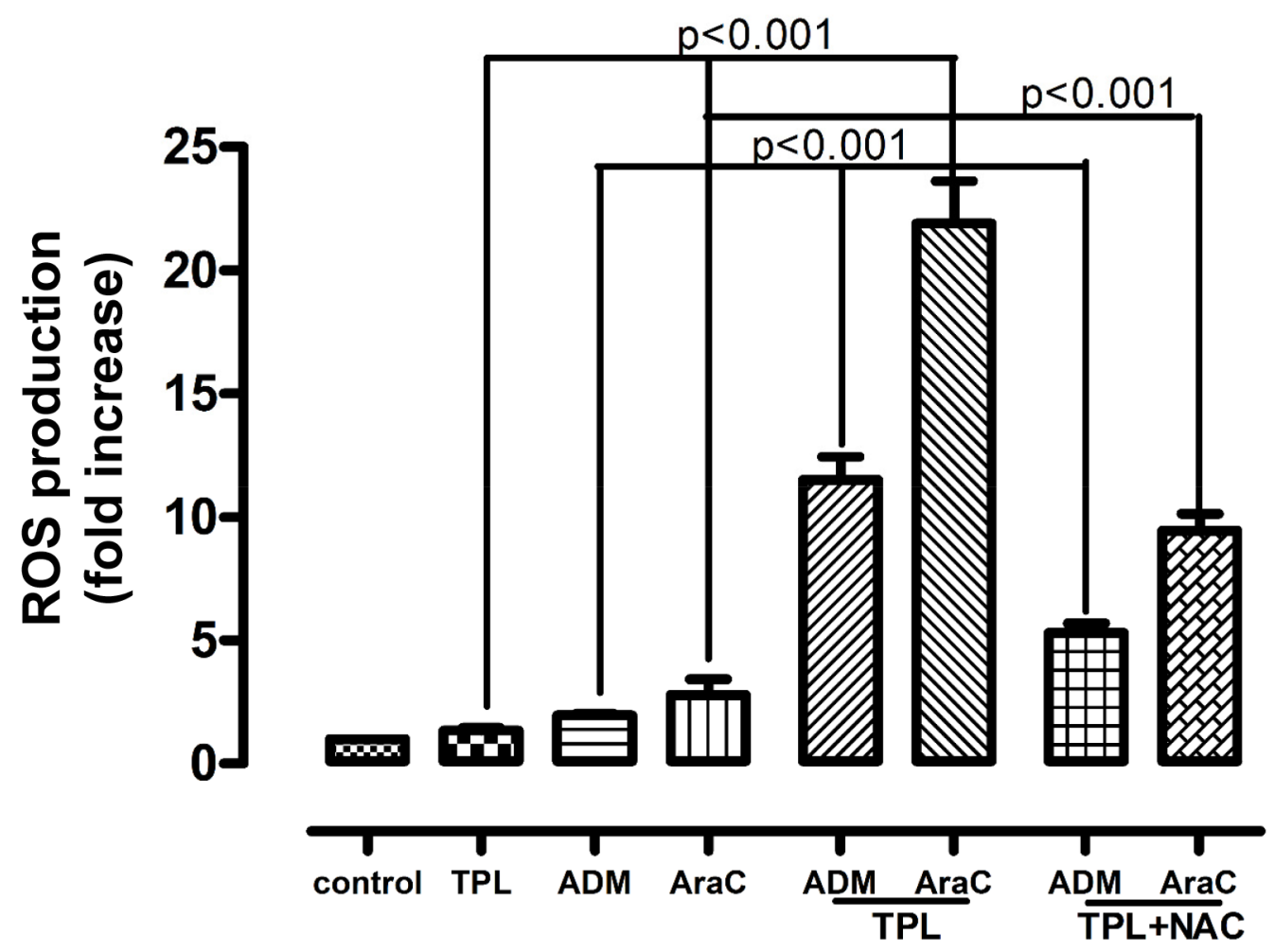

Figure 4: Combined treatment with TPL and araC or ADM induce ROS production in NALM-6/R cells, an event prevented by NAC. NALM-6/R cells were exposed to araC $(5 \mu \mathrm{M})$ or $\mathrm{ADM}(0.5 \mu \mathrm{M}) \pm \mathrm{TPL}\left(\mathrm{IC}_{20}: 10 \mathrm{nM}\right)$ for $12 \mathrm{~h}$, as well as addition of $30 \mathrm{mM}$ NAC for $2 \mathrm{~h}$ prior to combined treatments, after which ROS was measured using $\mathrm{H}_{2}$ DCFDA dye and flow cytometry. Values indicate fold increases, compared to untreated control, for three separate experiments (mean \pm SD).

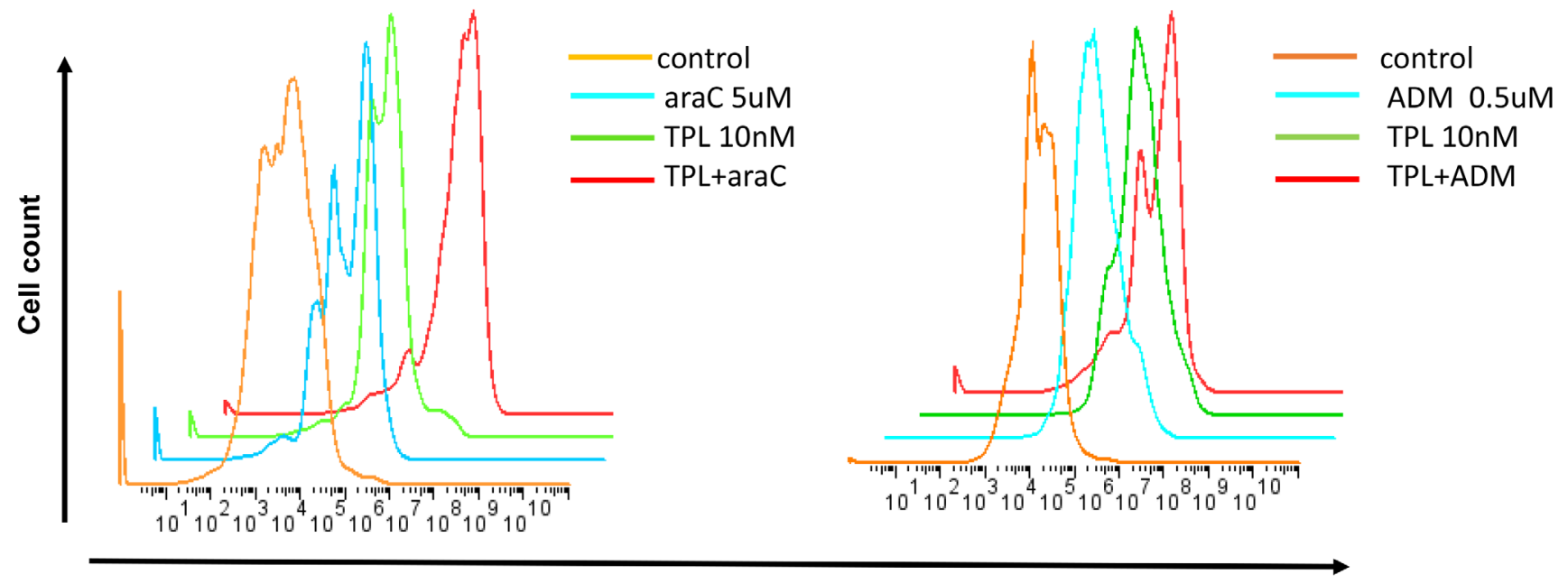

$\gamma$ H2A.X-FITC

Figure 5: Co-exposure to TPL and araC or ADM leads to increased expression of $\gamma \mathrm{H} 2 \mathrm{~A} . \mathrm{X}$, a marker for DNA doublestrand break. NALM-6/R cells were exposed to $\operatorname{araC}\left(5 \mu \mathrm{M}\right.$, left panel) or ADM $(0.5 \mu \mathrm{M}$, right panel $) \pm \mathrm{TPL}\left(\mathrm{IC}_{20}: 10 \mathrm{nM}\right)$ for $48 \mathrm{~h}$, after which cells were stained with anti- $\gamma \mathrm{H} 2 \mathrm{~A} . \mathrm{X}$ antibody for $1 \mathrm{~h}$, followed by FITC-conjugated secondary antibody for 30 min, and then subjected to flow cytometric analysis. 


\section{control TPL ADM AraC $\frac{T P L}{A D M A r a C}$}

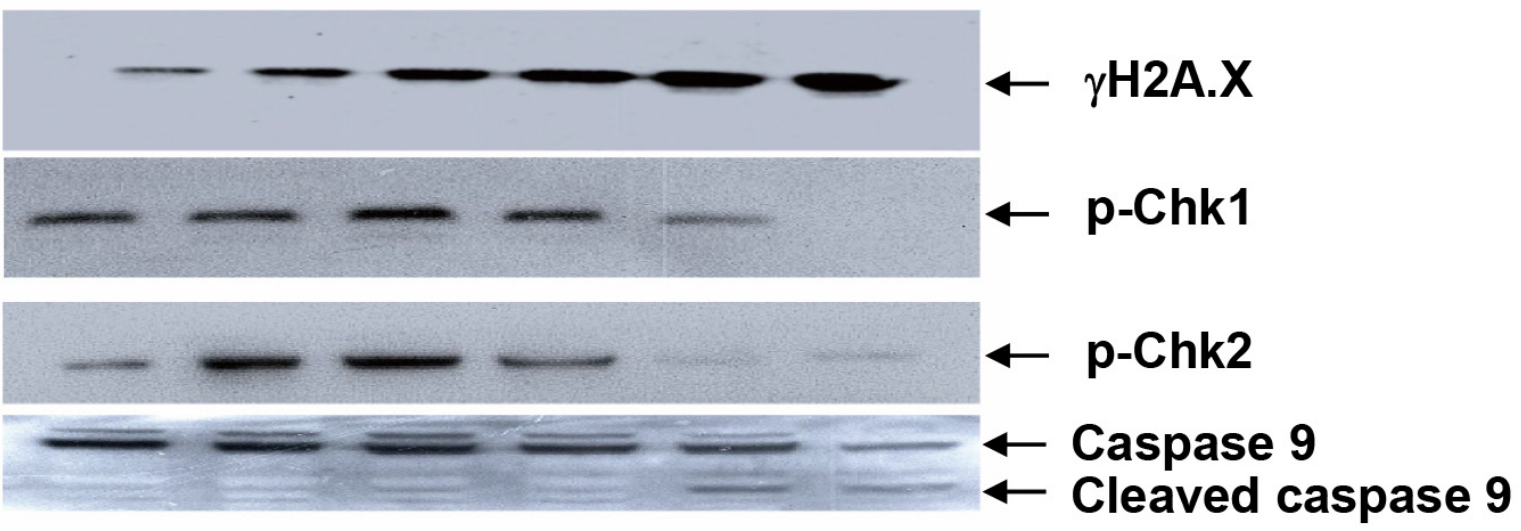

\section{$\beta$-actin}

Figure 6: Co-treatment with TPL and araC or ADM disrupts DNA damage checkpoint and induces caspase 9 activation in NALM-6/R cells. NALM-6/R cells were exposed to $\operatorname{araC}(5 \mu \mathrm{M})$ or ADM $(0.5 \mu \mathrm{M}) \pm \mathrm{TPL}\left(\mathrm{IC}_{20}: 10 \mathrm{nM}\right)$ for $48 \mathrm{~h}$, after which Western blotting analysis was performed to monitor expression of $\gamma \mathrm{H} 2 \mathrm{AX}$, p-Chk1, and pChk2, as well as cleavage/activation of caspase 9. The representative blots are shown for three independent experiments.

a

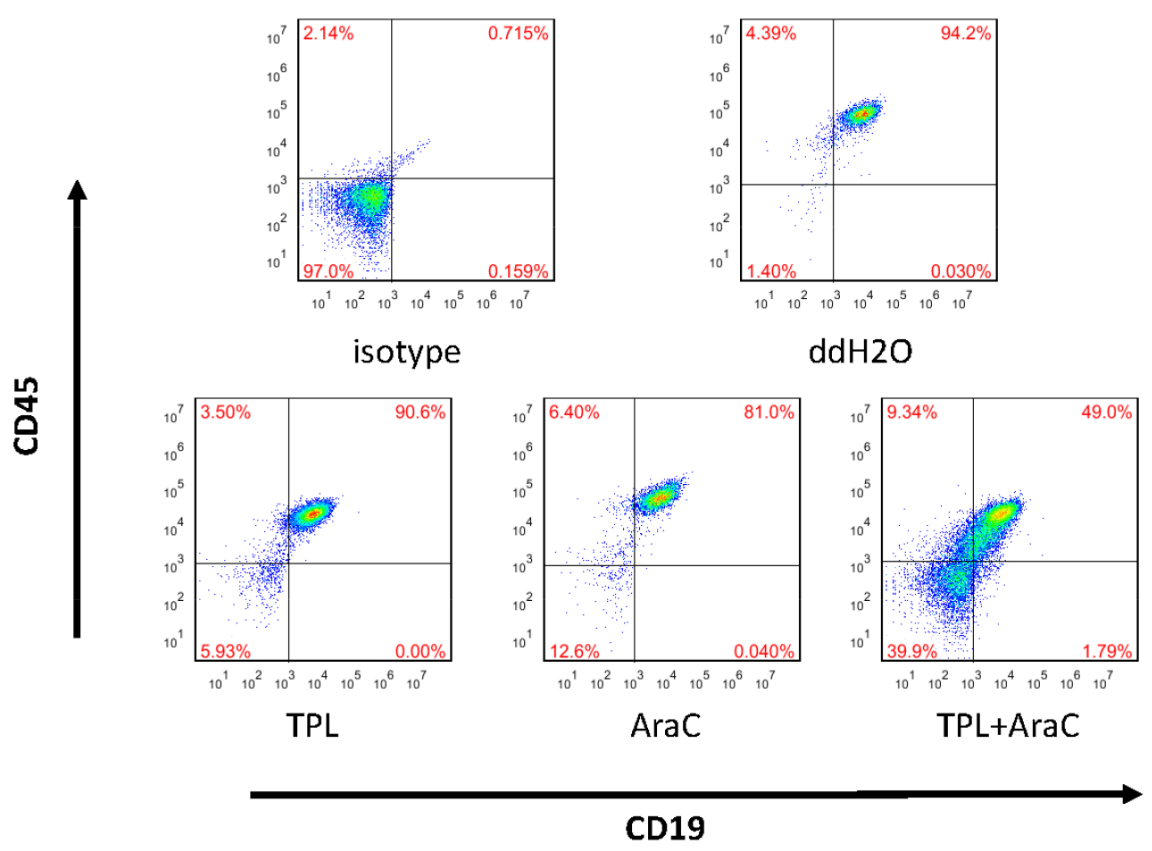

Figure 7: The regimen combining TPL with araC reduces tumor burden and prolongs animal survival in a mouse xenograft model of NALM-6/R cells. $5 \times 10^{5}$ NALM-6/R cells were subcutaneously injected via angular veins into sublethally irradiated adult NSI (NOD/SCID IL2rg-/-) mice. After 10 days, tumor-bearing mice were given intraperitoneally for 5 days with $100 \mu 1$ $\mathrm{ddH}_{2} \mathrm{O}$ as control, $10 \mathrm{mg} / \mathrm{kg}$ araC, $0.5 \mathrm{mg} / \mathrm{kg}$ TPL, or TPL in combination with araC, respectively. On day 16 post tumor cell inoculation, flow cytometry was performed to monitor the number of human CD45/CD19 double-positive cells in bone marrow a.;

(Continued) 
b
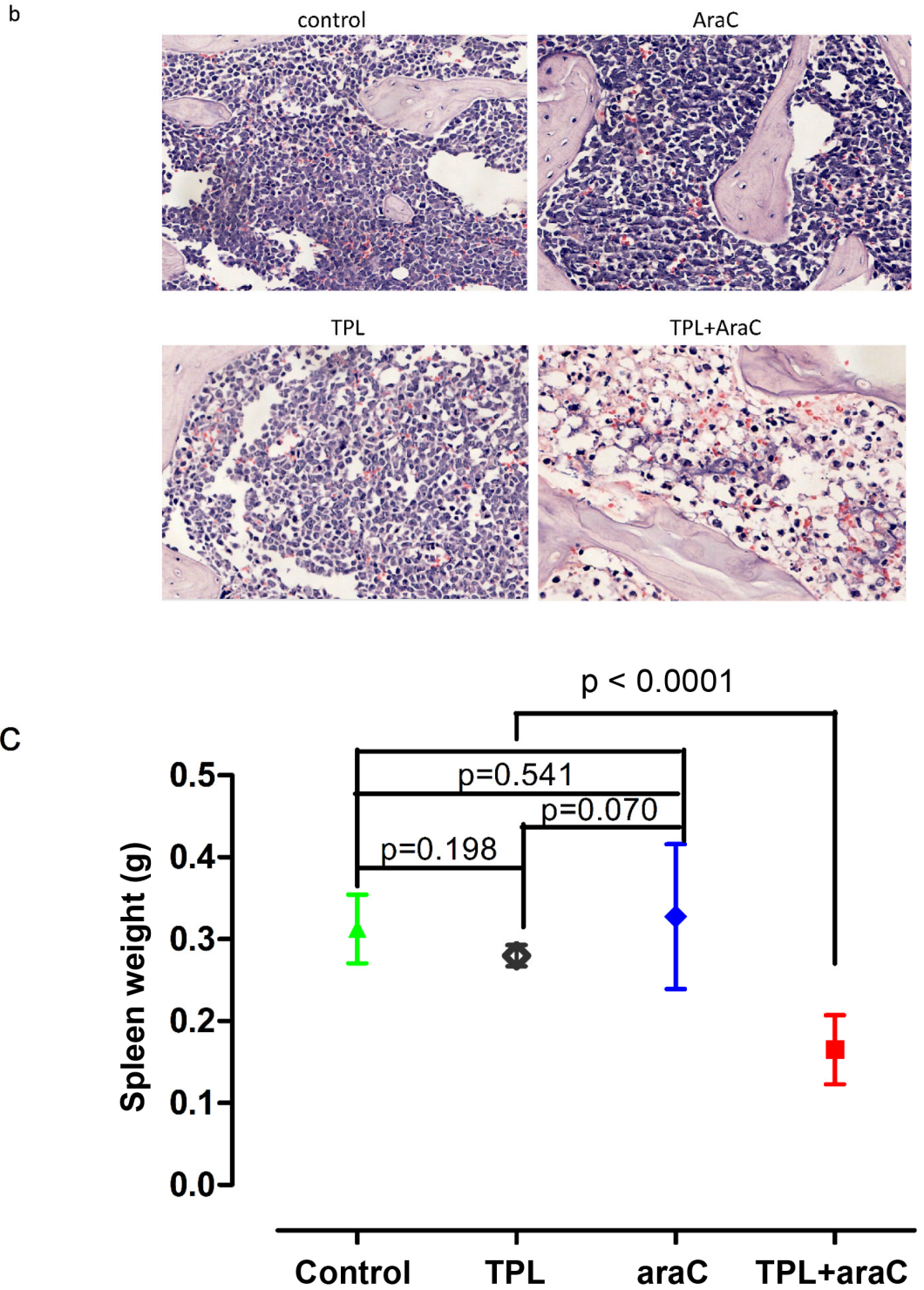

d

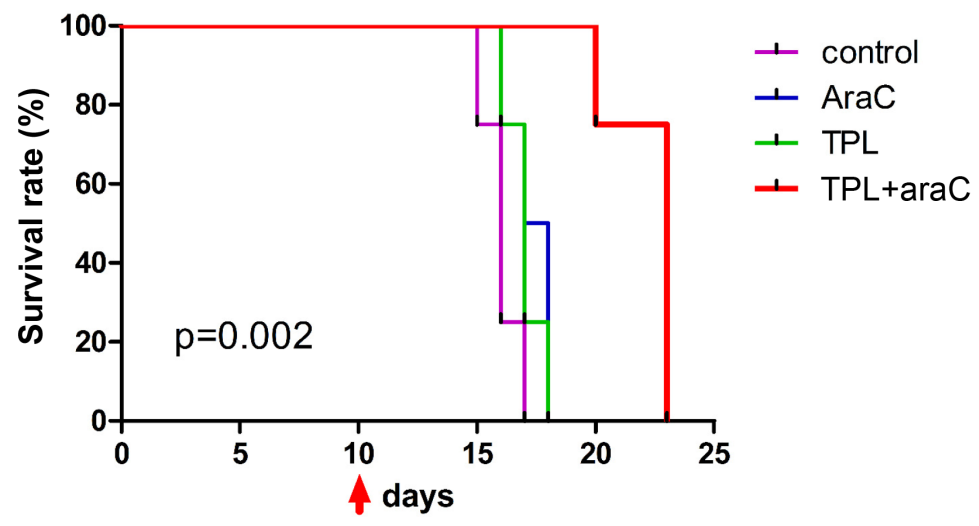

Drug administration

Figure 7 (Continued): bone marrow sections were stained with H \& E staining b.; spleen weight was measured c. Kaplan-Meier analysis was performed to assess animal survival $\mathbf{d}$. 
inhibited phosphorylation/activation of Chk1 and Chk2 induced by araC or ADM, accompanied by robust DNA damage and apoptosis. These results are consistent with a recent finding that TPL potentiates cisplatin-induced apoptosis by inhibiting DNA repair in lung cancer cells [26].

In summary, the present study demonstrates that low dose TPL could reverse chemoresistance of ALL cells to conventional DNA-damaging agents (e.g., araCand ADM), at least in part through induction of ROS, disruption of the DDR, and increase of DNA damage. It also provides the preclinical and pilot clinical evidence suggesting that the potential clinical benefits of adding TPL into standard DNA-damaging agents-based chemotherapy regimens warrant attention in treatment of relapsed and refractory ALL patients.

\section{MATERIALS AND METHODS}

\section{Chemicals and reagents}

Triptolide (TPL, $\mathrm{C}_{20} \mathrm{H}_{24} \mathrm{O}_{6}, \quad \mathrm{MW}: 360.40$ ), cytarabine ( $\operatorname{araC}, \mathrm{C}_{9} \mathrm{H}_{13} \mathrm{~N}_{3} \mathrm{O}_{5}, \mathrm{MW}: 243.22$ ), doxorubicin (ADM, $\mathrm{C}_{27} \mathrm{H}_{29} \mathrm{NO}_{11}$, MW: 543.52), and N-acetyl-Lcysteine (NAC) were purchased from Sigma-Aldrich (St. Louis, MO). TPL was dissolved in dimethyl sulfoxide (Sigma-Aldrich, Dorset, UK) as a $100 \mu \mathrm{M}$ stock solution, and was freshly diluted in culture medium before use. Cytarabine, doxorubicin, were dissolved in phosphate-buffered saline (PBS) as a 100 $\mathrm{mM}$ stock solution at $-20^{\circ} \mathrm{C}$. Light exposure was kept to a minimum for all drugs used.

\section{Cell culture and patient samples}

NALM-6 cells were obtained from the Institute of Hematology and Blood Diseases Hospital, Chinese Academy of Medical Sciences (Tianjin, China). The cells were routinely cultured in a RPMI 1640 medium (Invitrogen, USA), supplemented with 10\% fetal bovine serum at $37^{\circ} \mathrm{C}$ in a humidified $5 \% \mathrm{CO}_{2}$ incubator under standard conditions. AraC-resistant cells were established from the parental NALM-6 cells in our laboratory by continuous exposure to araC at low but gradually increasing concentrations, as described previously [27]. Finally, NALM-6/R cells were maintained in complete medium containing $5 \mu \mathrm{M}$ of araC.

Relapsed or refractory acute lymphoblastic leukemia (R/R ALL) cases were defined according to the classification in the NCCN guidelines. Twelve cases of $\mathrm{R} / \mathrm{R}$ ALL bone marrow or peripheral blood samples were obtained from the Nanfang Hospital, Southern Medical University. Major patient characteristics are summarized in Table 3. Mononuclear cells were isolated by standard Ficoll-Hypaque density centrifugation, and then cultured in RPMI-1640 supplemented with 10\% fetal bovine serum. The acquisition of human bone marrow samples were approved by the local institutes and the experimental use of human specimens was carried out in accordance with the institutional guidelines and the Declaration of Helsinki. Acquisition of bone marrow samples was performed with the informed consent of patients.

\section{In vitro cell proliferation assay}

NALM-6/R cells were cultured in 96-well culture plates at a density of $5 \times 10^{4}$ cells/well in a medium containing different concentrations of araC, ADM, or combinations of these agents with fixed concentrations of TPL ( $\mathrm{IC}_{20}: 10 \mathrm{nM}$ for $48 \mathrm{~h}$ ) at $37^{\circ} \mathrm{C}$ in a humidified $5 \%$ $\mathrm{CO}_{2}-95 \%$ air incubator. Cell inhibition was determined by a CCK8 assay, according to the manufacturer's instructions (Beyotime Company, China). After $48 \mathrm{~h}$, the cells were incubated in a $10 \mu \mathrm{CCK}-8$ solution for 2 $\mathrm{h}$ at $37^{\circ} \mathrm{C}$. The absorbance of each well was quantified at $450 \mathrm{~nm}$ with an automated ELESA reader. $\mathrm{IC}_{50}$ values were obtained using the logit method, and were determined from the results of at least 3 independent tests. The inhibition rate was calculated based on the following formula: Inhibition rate $(\%)=(1-$ absorbance of experimental group/absorbance of control group) $\mathrm{x}$ $100 \%$.

\section{Flow cytometric assays for cell apoptosis, mitochondrial membrane potential, reactive oxygen species and $\gamma \mathrm{H} 2 \mathrm{~A}$.X detection}

After treated for $48 \mathrm{~h}, 2 \times 10^{5}$ NALM-6/R cells were subjected to apoptosis assay using an Annexin V Apoptosis Detection Kit-APC (eBioscience Company, USA), following the manufacturer's instructions. For the mitochondrial membrane potential assessment, after different treatments for $48 \mathrm{~h}, 2 \times 10^{5}$ NALM$6 / \mathrm{R}$ cells were analyzed using a JC-1 fluorescent probe kit (Beyotime Company, China), following the manufacturer's instructions. To measure the intracellular reactive oxygen species (ROS) levels, about $2 \times 10^{5}$ $\mathrm{NALM} / \mathrm{R}$ cells subjected to different treatments were washed in PBS buffer twice, and then incubated in $1 \mathrm{ml}$ of serum-free RPMI 1640 medium containing $10 \mu \mathrm{M}$ of $\mathrm{H}_{2} \mathrm{DCFDA}$ for $30 \mathrm{~min}$ at $37^{\circ} \mathrm{C}$. The cells were harvested, and then washed in serum-free RPMI 1640 medium buffer twice to remove the remaining $\mathrm{H}_{2}$ DCFDA. The fluorescent intensity was measured by flow cytometry. For assessing the degree of DNA damage, $2 \times 10^{5}$ NALM-6/R cells were incubated for $15 \mathrm{~min}$ on ice in hybridization buffer (PBS containing $0.5 \%$ bovine serum albumin (BSA) and $0.25 \%$ Triton X-100). After centrifugation, the cells were incubated with rabbit monoclonal anti- $\gamma \mathrm{H} 2 \mathrm{~A} . \mathrm{X}$ antibody 
(Cell Signaling Technology, USA) for $1 \mathrm{~h}$, then washed with PBS and incubated with an FITC-conjugated mouse anti-rabbit IgG antibody (BD Pharmingen) for $30 \mathrm{~min}$ in the dark at room temperature.

\section{Western blot analysis}

The cytoplasmic protein $(50 \mu \mathrm{g} /$ lane $)$ from each sample was loaded onto a 10\% SDS-PAGE gel, then transferred to a PVDF membrane (Millipore, Billerica, MA, USA) and blotted with the appropriate antibodies. Non-specific binding was avoided by blocking the PVDF membrane with 5\% skimmed milk in TBS-T for $1 \mathrm{~h}$. The 5\% skimmed milk in TBS-T was also used to dilute primary antibodies (phospho- $\gamma-\mathrm{H} 2 \mathrm{AX}$, rabbit mAb,1: 1000, CST; Phospho-Chk1 (Ser345) Rabbit mAb, detecting Chk1 phosphorylated at serine 345,1: 1000, CST; Phospho-Chk2 (Thr68) Rabbit mAb, detecting Chk2 phosphorylated at Thr68,1: 1000, CST; caspase-9, mouse mAb, 1: 1000, CST) and HRP-conjugated secondary antibody (1: 10000; CST). The membranes were incubated in the primary antibodies overnight at $4{ }^{\circ} \mathrm{C}$ and in the secondary antibody for $1 \mathrm{~h}$ at room temperature. The quantities of protein loaded were verified by staining the same membranes with anti- $\beta$-actin antibody (rabbit mAb 1: 1000, CST). The signals were detected on X-ray films using an enhanced chemiluminescence western blotting detection kit (Amersham Pharmacia Biotech). $\beta$-Actin was included as a loading control.

\section{Animal study}

All animal experiments were performed in the Laboratory Animal Center of the Guangzhou Institute of Biomedicine and Health (GIBH), and the animal procedures were approved by the Animal Welfare Committee of GIBH. To generate a mouse model of araC-resistant ALL, we subcutaneously injected NALM$6 / \mathrm{R}$ cells $\left(5 \times 10^{5}\right)$ into the angular veins of sublethally irradiated adult NSI (NOD/SCID IL2rg-/-) mice (20-30 g body weight; 2-3 months of age). Ten days later, 16 tumorbearing mice were divided into 4 groups and injected intraperitoneally with $100 \mu \mathrm{l}$ with $\mathrm{dd}_{2} \mathrm{O}$, araC $(10 \mathrm{mg} /$ $\mathrm{kg}$, half of maximum tolerated dose in SCID mice [28]), TPL $(0.5 \mathrm{mg} / \mathrm{kg}, 25 \%$ of lethal concentration [29]), or TPL in combination with araC for 5 days, respectively. We evaluated the responses to this treatment by measuring the overall survival times, the weights of the spleens and the percentages of human CD45/CD19 double-positive cells in the bone marrow, as assessed by flow cytometry. The tissue samples were fixed in formaldehyde and further embedded in paraffin.

\section{Statistical analysis}

Data was expressed as the mean \pm standard deviation (S.D.) for at least three independent experiments and compared using the Student $t$-test. Multiple-group comparisons were performed using the One-way analysis of variance (ANOVA) followed by the Bonferroni posthoc test. Survival were estimated using the Kaplan-Meier analysis and compared using the log-rank test. $P$ values $<0.05$ were considered statistically significant. Statistical analyses were performed using SPSS 20.0 software (La Jolla, CA).

\section{ACKNOWLEDGMENTS}

This work was supported by the National Natural Science Foundation of China (No. 81570156 and No. 81400104) and the Guangdong Provincial Basic Research Program, P. R. China (No. 2015B020227003).

\section{CONFLICTS OF INTEREST}

All authors declare that there are no conflicts of interest.

\section{REFERENCES}

1. Annino L, Vegna ML, Camera A, Specchia G, Visani G, Fioritoni G, Ferrara F, Peta A, Ciolli S, Deplano W, Fabbiano F, Sica S, Di Raimondo F, et al. Treatment of adult acute lymphoblastic leukemia (ALL): long-term follow-up of the GIMEMA ALL 0288 randomized study. Blood. 2002; 99:863-871.

2. Bassan R, Hoelzer D. Modern therapy of acute lymphoblastic leukemia. Journal of clinical oncology. 2011; 29:532-543.

3. Fielding AK, Richards SM, Chopra R, Lazarus HM, Litzow MR, Buck G, Durrant IJ, Luger SM, Marks DI, Franklin IM, McMillan AK, Tallman MS, Rowe JM, Goldstone AH, Medical Research Council of the United Kingdom Adult ALLWP and Eastern Cooperative Oncology G. Outcome of 609 adults after relapse of acute lymphoblastic leukemia (ALL); an MRC UKALL12/ECOG 2993 study. Blood. 2007; 109:944-950.

4. Gokbuget N, Stanze D, Beck J, Diedrich H, Horst HA, Huttmann A, Kobbe G, Kreuzer KA, Leimer L, Reichle A, Schaich M, Schwartz S, Serve H, et al. Outcome of relapsed adult lymphoblastic leukemia depends on response to salvage chemotherapy, prognostic factors, and performance of stem cell transplantation. Blood. 2012; 120:2032-2041.

5. Kupchan SM, Court WA, Dailey RG, Jr., Gilmore CJ, Bryan RF. Triptolide and tripdiolide, novel antileukemicditerpenoidtriepoxides from Tripterygium wilfordii. J Am Chem Soc. 1972; 94:7194-7195.

6. Yang L, Wei DD, Chen Z, Wang JS, Kong LY. Reversal effects of traditional Chinese herbs on multidrug resistance in cancer cells. Nat Prod Res. 2011; 25:1885-1889.

7. Chen F, Liu Y, Wang S, Guo X, Shi P, Wang W, Xu B. Triptolide, a Chinese herbal extract, enhances drug 
sensitivity of resistant myeloid leukemia cell lines through downregulation of HIF-1alpha and Nrf2. Pharmacogenomics. 2013; 14:1305-1317.

8. Wang C, Liu B, Xu X, Zhuang B, Li H, Yin J, Cong M, $\mathrm{Xu} \mathrm{W}, \mathrm{Lu} \mathrm{A}$. Toward targeted therapy in chemotherapyresistant pancreatic cancer with a smart triptolide nanomedicine. Oncotarget. 2016; 7:8360-8372. doi: 10.18632/oncotarget.7073.

9. Zhong YY, Chen HP, Tan BZ, Yu HH, Huang XS. Triptolide avoids cisplatin resistance and induces apoptosis via the reactive oxygen species/nuclear factor-kappaB pathway in SKOV3 platinum-resistant human ovarian cancer cells. Oncol Lett. 2013; 6:1084-1092.

10. Ly JD, Grubb DR, Lawen A. The mitochondrial membrane potential (deltapsi(m)) in apoptosis; an update. Apoptosis. 2003; 8:115-128.

11. Yang F, Kemp CJ, Henikoffa S. Anthracyclines induce double-strand DNA breaks at active gene promoters. Mutat Res. 2015; 773:9-15.

12. Kufe DW, Major PP, Egan EM, Beardsley GP. Correlation of cytotoxicity with incorporation of ara-C into DNA. The Journal of biological chemistry. 1980; 255:8997-8900.

13. Mah LJ, El-Osta A, Karagiannis TC. gammaH2AX: a sensitive molecular marker of DNA damage and repair. Leukemia. 2010; 24:679-686.

14. Fernandez-Capetillo O, Lee A, Nussenzweig M, Nussenzweig A. H2AX: the histone guardian of the genome. DNA repair. 2004; 3:959-967.

15. Su D, Song Y, Li R. [Comparative clinical study of rheumatoid arthritis treated by triptolide and an ethyl acetate extract of Tripterygium wilfordii]. Zhong Xi Yi Jie He ZaZhi. 1990; 10:144-146, 131.

16. Testi AM, Del Giudice I, Arcese W, Moleti ML, Giona F, Basso G, Biondi A, Conter V, Messina C, Rondelli R, Micozzi A, Micalizzi C, Barisone E, et al. A single high dose of idarubicin combined with high-dose ARA-C for treatment of first relapse in childhood 'high-risk' acute lymphoblastic leukaemia: a study of the AIEOP group. British journal of haematology. 2002; 118:741-747.

17. Tedeschi A, Montillo M, Strocchi E, Cafro AM, Tresoldi E, Intropido L, Nichelatti M, Marbello L, Barate C, Camaggi CM, Morra E. High-dose idarubicinin combination with Ara-C in patients with relapsed or refractory acute lymphoblastic leukemia: a pharmacokinetic and clinical study. Cancer chemotherapy and pharmacology. 2007; 59:771-779.

18. Tardi P, Johnstone S, Harasyrn N, Xie SW, Harasyrn T, Zisman N, Harvie P, Bermudes D, Mayer L. In vivo maintenance of synergistic cytarabine:daunorubicin ratios greatly enhances therapeutic efficacy. Leukemia research. 2009; 33:129-139.

19. Dinner S, Lee D, Liedtke M. Current therapy and novel agents for relapsed or refractory acute lymphoblastic leukemia. Leukemia \& lymphoma. 2014; 55:1715-1724.

20. Rowe LA, Degtyareva N, Doetsch PW. DNA damageinduced reactive oxygen species (ROS) stress response in Saccharomyces cerevisiae. Free RadicBiol Med. 2008; 45:1167-1177.

21. Hamanaka RB, Chandel NS. Mitochondrial reactive oxygen species regulate cellular signaling and dictate biological outcomes. Trends Biochem Sci. 2010; 35:505-513.

22. Fruehauf JP, Meyskens FL, Jr. Reactive oxygen species: a breath of life or death? Clin Cancer Res. 2007; 13:789-794.

23. Wang X, Zhang JJ, Sun YM, Zhang J, Wang LR, Li JC, Liu H. Triptolide Induces Apoptosis and Synergizes with Cisplatin in Cisplatin-Resistant HNE1/DDP Nasopharyngeal Cancer Cells. Folia biologica. 2015; 61:195-202.

24. Carter BZ, Mak DH, Schober WD, McQueen T, Harris D, Estrov Z, Evans RL, Andreeff M. Triptolide induces caspase-dependent cell death mediated via the mitochondrial pathway in leukemic cells. Blood. 2006; 108:630-637.

25. Shao RG, Cao CX, Pommier Y. Abrogation of Chk1mediated S/G2 checkpoint by UCN-01 enhances araC-induced cytotoxicity in human colon cancer cells. ActaPharmacol Sin. 2004; 25:756-762.

26. Wang G, Wang X, Xu X. Triptolide potentiates lung cancer cells to cisplatin-induced apoptosis by selectively inhibiting the NER activity. Biomarker research. 2015; 3:17.

27. Qi J, Peng H, Gu ZL, Liang ZQ, Yang CZ. [Establishment of an imatinibresistant cell line K562/G01 and its characterization]. ZhonghuaXue Ye XueZaZhi. 2004; 25:337-341.

28. Hosler, G.A., R. Bash, R.H. Scheuermann, Kinetics of early therapeutic response as measured by quantitative PCR predicts survival in a murine xenograft model of human $\mathrm{T}$ cell acute lymphoblastic leukemia. Leukemia, 2000. 14: p. $1215-24$.

29. Xu L, Qiu Y, Xu H, Ao W, Lam W, Yang X. Acute and subacute toxicity studies on triptolide and triptolide-loaded polymeric micelles following intravenous administration in rodents. Food Chem Toxicol. 2013; 57:371-379. 